Available online http://jurnal.unimed.ac.id/2012/index.php/einstein

\title{
Analisis Pengukuran Daya Hantar Listrik Dan Komponen- Komponen Air Sumur Gali Dengan Konduktivitimeter Di Desa Sialang Buah Kecamatan Teluk Mengkudu Kabupaten Serdang Bedagai
}

\author{
Rappel Situmorang dan Mentari*
}

Jurusan Fisika, Fakultas Matematika dan Ilmu Pengetahuan Alam, Universitas Negeri Medan, Indonesia

Diterima Agustus 2016; Disetujui September 2016; Dipublikasikan Nopember 2016

\begin{abstract}
Abstrak
Tujuan dari penelitian ini adalah untuk mengetahui tingkat Daya Hantar Listrik (DHL) air sumur gali di Desa Sialang Buah.Dan tingkat intrusi pada air sumur gali suatu kualitas air yang selama ini dikonsumsi oleh warga. Dalam penelitian ini digunakan 5 sampel air laut dan 20 sampel air sumur gali di Desa Sialang Buah.Untuk mengetahui besarnya Daya Hantar Listrik (DHL) dari tiap sampel tersebut digunakan konduktivitimeter. Hasil yang diperoleh, air sumur gali di Desa Sialang Buah memiliki kualitas air dengan kategori terintrusi sedang, terintrusi agak tinggi dan terintrusi

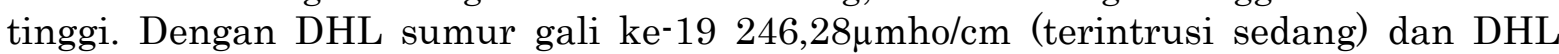

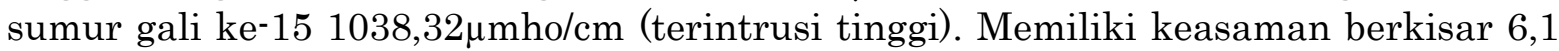
- 7,5. Dan sumur gali ke-17 memiliki $\mathrm{pH}$ diatas standar kelayakan air untuk dikonsumsi yaitu 8,1. Namun melihat kualitas air sumur gali dari 20 sampel yang diteliti bahwa air sumur gali tersebut telah terintrrusi maka dapat dinyatakan tidak layak/tidak dapat dikonsumsi. Air sumur gali di Desa Sialang Buah Kecamatan Teluk Mengkudu Kabupaten Serdang Bedagai memiliki kualitas air dengan kategori terintrusi sedang, terintrusi agak tinggi dan terintrusi tinggi.
\end{abstract}

Kata Kunci : Intrusi Air Laut, Daya Hantar Listrik dan Konduktivitimeter

How to Cite: Rappel Situmorang dan Mentari, (2016), Analisis Pengukuran Daya Hantar Listrik
Dan Komponen-Komponen Air Sumur Gali Dengan Konduktivitimeter Di Desa Sialang
\begin{tabular}{lr} 
Buah Kecamatan Teluk Mengkudu Kabupaten Serdang Bedagai, Jurnal Einsten Prodi Fisika \\
FMIPA Unimed, 4 (1):15-21. & p-ISSN:2338-1981 \\
\hline${ }^{*}$ Corresponding author: & e-ISSN $: 2407-747 x$ \\
E-mail : situmorangrappel@gmail.com
\end{tabular} 


\section{PENDAHULUAN}

Bumi lebih dari $80 \%$ terdiri dari air, namun hanya $2 \%$ yang merupakan air tanah, sisanya merupakan lautan, juga berupa air permukaan.Dua persen inilah yang dipakai oleh seluruh penduduk bumi sebagai pemenuhan kebutuhan primer karena air tanah merupakan salah satu sumberdaya air yang baik untuk air bersih dan air minum, dibandingkan dengan sumber air lainnya karena adanya berbagai keuntungan dibanding dengan sumber air lainnya.

Kekeringan menyebabkan air tanah dalam sumur menjadi sedikit bahkan kering karena infiltrasi berkurang sebagai dampak dari curah hujan yang sedikit di kawasan ini.Air tanah dalam sumur tersebut mengalami fluktuasi baik secara alami (kekeringan) maupun secara tidak alami (pemanfaatan air oleh manusia) sehingga air tanah bisa terdesak oleh air laut sehingga terjadi intrusi air laut. (Nurrohim, 2012)

Semakin banyaknya penduduk yang membangun sumur gali di desa Sialang Buah, maka semakin besar pula potensi terjadinya intrusi air laut didesa tersebut karena hampir seluruh warga di desa Sialang Buah menggunakan air sumur gali sebagai sumber air bersih untuk konsumsi keseharian warga.

Pada beberapa tahun yang lalu Pemerintah telah membangun beberapa sumur bor untuk dapat digunakan oleh warga desa Sialang Buah, tetapi berdasarkan informasi yang peneliti terima dari warga bahwa air sumur bor tersebut hanya dapat menghasilkan air apabila air laut telah pasang dan apabila air laut surut maka sumur bor tidak dapat berfungsi.

Bahkan menurut warga, air sumur bor tersebut tidak berfungsi dengan efisien karena dalam beberapa tahun air yang dihasilkan oleh sumur bor tersebut lambat-laun berubah menjadi menguning sehingga tidak dapat digunakan sebagai sumber air bersih.Dengan demikian sumur bor yang dibangun oleh Pemerintah tersebut tidak dipergunakan lagi oleh warga hingga saat ini.Dan masing-masing warga membangun sumur gali untuk dapat memperoleh air bersih.

Sumur gali yang dibangun oleh warga desa Sialang Buah memiliki air yang jernih dan rasa yang tidak terlalu asin, namun air tersebut memiliki bau yang sedikit mengganggu serta warga juga warga merasa bahwa rasa air yang mereka konsumsi tidak memiliki rasa yang sama dengan air sumur yang berasal dari daerah yang jauh dari tepi pantai (Soehartono. 2013).

Warga desa Sialang Buah tidak mengetahui bahwa ada kemungkinan air laut yang terintrusi kedalam air tanah tersebut mengandung zat-zat kimia yang dapt merusak kualitas air tanah sehingga air sumur gali yang dikonsumsi oleh warga sudah tidak layak untuk dikonsumsi lagi karena mengangdung zat-zat terlarut berbahaya yang akan mengganggu kesehatan warga desa Sialang Buah.

Maka peneliti ingin melakukan penelitian mengenai "Analisis Pengukuran Daya Hantar Listrik (DHL) dan Komponen - Komponen Air Sumur Gali dengan Konduktivitimeter di Desa Sialang Buah Kecamatan Teluk Mengkudu Kabupaten Serdang Bedagai".Dengan harapan, hasil dari penelitian ini dapat meningkatkan upaya dari pihak terkait dalam penyediaan air bersih layak konsumsi bagi warga desa Sialang Buah.

\section{METODE PENELITIAN \\ Peralatan yang Digunakan}

Alat ukur yang biasanya digunakan untuk mengukur nilai daya hantar listrik (DHL) dalam suatu larutan disebut dengan konduktivitimeter. Konduktivimeter biasanya sudah berkaitan dengan alat ukur parameter lain seperti $\mathrm{pH}$, TDS 
dan salinitas. Pengukuran dari daya hantar listrik (DHL) sangat dipengaruhi oleh nilai temperatur. Bahkan suatu larutan standar konduktivitas pun akan memberikan perbedaan yang besar apabila terjadi perbedaan temperatur. Hal ini dapat dibuktikan dengan cara mengukur nilai standar tersebut pada suhu yang sudah tertera disertifikat standar, kemudian mengukur larutan yang sama pada temperatur yang berbeda.

\section{Pengolahan Data}

Analisa Model regresi Linear Berganda

Penelitian ini dilakukan dengan metode survey dan mengukur Daya Hantar Listrikair tanah yaitu pada sumur gali, Pengujian ini dilakukan dengan model analisa model regresi berganda dengan persamaan :

$$
\hat{\mathrm{Y}}=a_{0}+a_{1} X_{1}+a_{2} X_{2}+. .+a_{k} X_{k}
$$

Di dalam penelitian ini variabel terikat adalah $\hat{\mathrm{Y}}$ (Daya hantar listrik), dan variabel-variabel bebas adalah kedalaman sumur gali $\left(X_{1}\right)$ dan jarak sumur gali dari garis pantai $\left(X_{2}\right)$, maka bentuk persamaan regresinya:

$$
\hat{\mathrm{Y}}=a_{0}+a_{1} X_{1}+a_{2} X_{2}
$$

\section{Analisis Varian (Uji F)}

Untuk menguji linieritas persamaan (1) digunakan uji $\mathrm{F}$ dengan persamaan:

$$
F=\frac{J K_{r e g} / k}{J K_{r e s} /(n-k-1)}
$$

Jumlah kuadrat-kuadrat regresi dapat dihitung dengan persamaan:

$$
J K_{\text {reg }}=a_{1} \Sigma X_{1 i} y_{i}+a_{2} \Sigma X_{2 i} y_{i}+
$$

Jumlah kuadrat-kuadrat residu dapat dihitung dengan persamaan :

$$
J K_{r e s}=\Sigma\left(Y_{i}-\hat{Y}_{i}\right)^{2}
$$

Jika Fn yang diperoleh melalui persamaan 4 lebih besar dari $F_{t}$ maka variabel-variabel $X_{1}, X_{2}, \ldots . ., X_{n}$ secara nyata sama-sama berpengaruh terhadap $\mathrm{Y}$ dengan persamaan regresi linier seperti persamaan 2. Untuk mengetahui seberapa kuat hubungan antara variabel-variabel $X_{1} \operatorname{dan} X_{2}$ terhadap Y digunakan koefisien korelasi berganda dengan persamaan:

$$
R^{2}=\frac{J K_{r e g}}{\Sigma y_{i}^{2}}
$$

$$
\begin{aligned}
& \mathrm{R}^{2}=\text { Koefisien determinasi }
\end{aligned}
$$

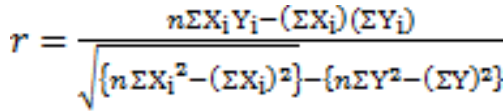

Berdasarkan indeks korelasi $-1 \leq \mathrm{r} \leq 1$

Interpretasi koefisien korelasi:

$r=1$ maka kedua variable dikatakan berhubungan erat secara positif, artinya makin besar variable pertama dari suatu individu, makin besar pula nilai variable kedua pada individu yang sama

$\mathrm{r}=-1$ maka kedua variable dikatakan berhubungan erat secara negative, artinya makin kecil variable pertama dari suatu individu, makin kecil pula nilai variable ke dua pada individu yang sama

$r=0$ maka kedua variable tidak berhubungan sam sekali.

\section{Analisa Air Laut dan Air Sumur}

.$+a_{k} \Sigma X_{k i} y_{i}$ Pada pengolahan data nilai DHL pada sample dilakukan pada suhu yang sama yaitu $25^{\circ} \mathrm{C}$. Untuk mendapatkan nilai DHL pada suhu $25^{0} \mathrm{C}$ maka dilakukan interpolasi linier dengan menggunakan persamaan :

$$
\operatorname{DHL}\left(\mu \mathrm{mhos} / \mathrm{cm}, 25^{\circ} \mathrm{C}\right)=\frac{25}{t_{\text {air }}} D H L_{p}
$$


Rappel Situmorang dan Mentari, Analisis Pengukuran Daya Hantar Listrik Dan KomponenKomponen Air Sumur Gali Dengan Konduktivitimeter Di Desa Sialang Buah Kecamatan Teluk Mengkudu Kabupaten Serdang Bedagai

Untuk menentukan tingkat intrusi air laut pada sumur gali, digunakan rumus sebagai berikut:

$$
Q_{i}=\frac{i(n+1)}{4}
$$

Berdasarkan nilai ppm dan DHL pada suhu tertentu yang dilakukan dilaboratorium dapat dihitung DHL pada suhu $25^{\circ} \mathrm{C}$ dengan persamaan:

$$
D H L_{25}=\frac{D H L_{t}(p p m)}{1+0,0191(t-25)}
$$

\section{HASIL PENELITIAN PEMBAHASAN}

\section{Air Laut dan Air Sumur Gali}

Sampel air laut diambil dari 5 sampel dan air sumur gali atas 20 sampel, dengan data DHL diukur dengan konduktivitimeter dengan hasil dalam tabel 1 dan 2

Tabel 1. Hasil Pengukuran DHL Air

\begin{tabular}{|c|c|c|c|c|}
\hline No. & $\begin{array}{c}\text { Kode } \\
\text { Sampel }\end{array}$ & $\begin{array}{c}\text { Jarak } \\
(\mathrm{m})\end{array}$ & $\begin{array}{c}\text { DHL } \\
(\mu \mathrm{mho} / \mathrm{cm})\end{array}$ & Suhu $(\circ \mathrm{C})$ \\
\hline & Titik & & & \\
\hline 1 & Acuan & 25 & 19900 & 25,9 \\
\hline 2 & AL 1 & 125 & 20400 & 25,9 \\
\hline 3 & AL 2 & 625 & 20900 & 25,9 \\
\hline 4 & AL 3 & 1625 & 21100 & 25,9 \\
\hline 5 & AL 4 & 3625 & 21400 & 26,9 \\
\hline
\end{tabular}

$$
\text { Laut }
$$

Tabel 2. Hasil Pengkuran DHL Air Sumur Gali

\begin{tabular}{cccccc}
\hline \multicolumn{2}{c}{$\begin{array}{c}\text { Kode } \\
\text { No. }\end{array}$} & $\begin{array}{c}\text { Sampel } \\
(\mathrm{m})\end{array}$ & $\begin{array}{c}\text { Kedalaman } \\
(\mathrm{m})\end{array}$ & $\begin{array}{c}\text { DHL } \\
(\mu \mathrm{mho} / \mathrm{cm})\end{array}$ & $\begin{array}{c}\text { Suhu } \\
(\circ \mathrm{C})\end{array}$ \\
\hline 1 & SG 1 & 3.296 & 2 & 672 & 26,9 \\
2 & SG 2 & 3.346 & 3 & 327 & 26,9 \\
3 & SG 3 & 3.396 & 2 & 512 & 27,0 \\
4 & SG 4 & 3.446 & 2 & 411 & 27,0 \\
5 & SG 5 & 3.516 & 3 & 372 & 26,9 \\
6 & SG 6 & 3.586 & 4 & 267 & 27,0 \\
7 & SG 7 & 3.656 & 2 & 270 & 27,2 \\
8 & SG 8 & 3.726 & 3 & 360 & 27,0 \\
9 & SG 9 & 3.826 & 4 & 386 & 27,0 \\
10 & SG 10 & 3.926 & 4 & 509 & 27,1 \\
11 & SG 11 & 4.026 & 4 & 407 & 26,9 \\
12 & SG 12 & 4.126 & 6 & 389 & 27,0 \\
13 & SG 13 & 4.326 & 3 & 612 & 27,0
\end{tabular}

\begin{tabular}{llllcl}
14 & SG 14 & 4.396 & 3 & 691 & 27,1 \\
15 & SG 15 & 4.466 & 4 & 1138 & 27,4 \\
16 & SG 16 & 4.536 & 3 & 991 & 27,3 \\
17 & SG 17 & 4.786 & 4 & 573 & 27,1 \\
18 & SG 18 & 5.036 & 5 & 484 & 27,0 \\
19 & SG 19 & 5.286 & 7 & 265 & 26,9 \\
20 & SG 20 & 5.536 & 8 & 807 & 26,9 \\
\hline
\end{tabular}

Perhitungan Daya Hantar Listrik (DHL) Air Laut dan Air Sumur Gali Pada Suhu $25^{\circ} \mathrm{C}$

Data DHL air laut dan sumur gali sesuai suhu $25^{\circ} \mathrm{C}$ seperti pada tabel 13

Tabel 3.Data Hasil Pengukuran Daya Hantar Listrik Air Laut Pada Suhu $25^{\circ} \mathrm{C}$

\begin{tabular}{ccccc}
\hline & $\begin{array}{c}\text { Kode } \\
\text { No. }\end{array}$ & $\begin{array}{c}\text { Sampel } \\
(\mu \mathrm{mho} / \mathrm{cm})\end{array}$ & $\begin{array}{c}\text { Suhu } \\
\left({ }^{\circ} \mathrm{C}\right)\end{array}$ & $\begin{array}{c}\text { DHL } \\
(\mu \mathrm{mho} / \mathrm{cm}, 25 \circ \mathrm{C})\end{array}$ \\
\hline & Titik & & & \\
1 & Acuan & 19900 & 25,9 & 19208,49 \\
2 & AL 1 & 20400 & 25,9 & 19691,12 \\
3 & AL 2 & 20900 & 25,9 & 20173,75 \\
4 & AL 3 & 21100 & 25,9 & 20366,79 \\
5 & AL 4 & 21400 & 26,9 & 20576,92 \\
\hline
\end{tabular}

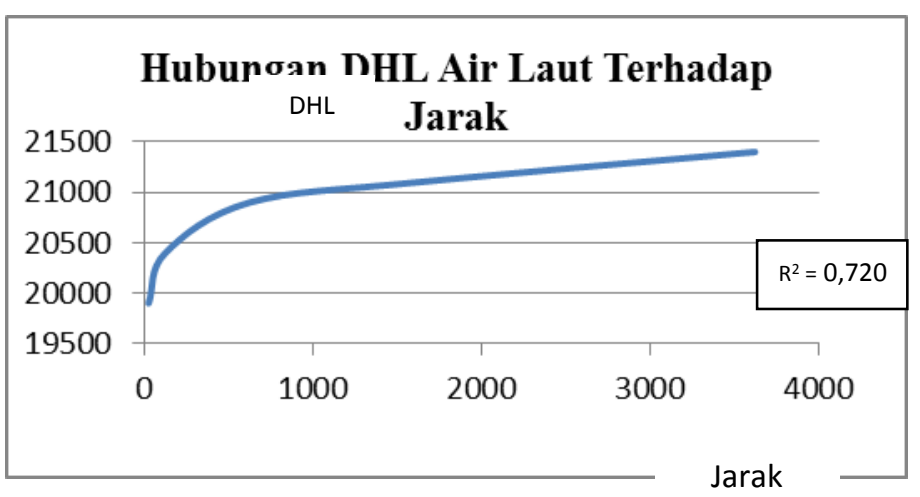
Gambar 1. Grafik Hubungan Antara Jarak Sampel Air Laut Dari Garis Pantai (m) Terhadap DHL Air Laut ( $\mu m h o / C m$, $25^{\circ} \mathrm{c}$ )

Dari DHL yang yang telah diukur dapat ditentukan klasifikasinya seperti tabel 4. Data DHL air laut dan sumur gali sesuai suhu $25^{\circ} \mathrm{C}$ seperti pada tabel 4 
Tabel 4. Klasifikasi Intrusi Air Laut Pada Sumur Gali Berdasarkan Daya Hantar Listrik (DHL)

\begin{tabular}{|c|c|c|c|c|}
\hline $\begin{array}{c}\text { Kode } \\
\text { Sampel }\end{array}$ & $\begin{array}{l}\text { Jarak } \\
(\mathrm{m})\end{array}$ & $\begin{array}{c}\text { Kedalaman } \\
(\mathrm{m})\end{array}$ & $\begin{array}{c}\text { DHL } \\
\left(\mu \mathrm{mho} / \mathrm{cm}, 25^{\circ} \mathrm{C}\right)\end{array}$ & $\begin{array}{l}\text { Klasifikasi } \\
\text { Intrusi }\end{array}$ \\
\hline SG 1 & 3296 & 2 & 624,54 & $\begin{array}{l}\text { Terintrusi } \\
\text { Tinggi } \\
\text { Terintrusi }\end{array}$ \\
\hline SG 2 & 3346 & 3 & 303,90 & $\begin{array}{l}\text { Sedang } \\
\text { Terintrusi } \\
\text { Agak }\end{array}$ \\
\hline SG 3 & 3396 & 2 & 474,07 & $\begin{array}{l}\text { Tinggi } \\
\text { Terintrusi }\end{array}$ \\
\hline SG 4 & 3446 & 2 & 380,50 & $\begin{array}{l}\text { Sedang } \\
\text { Terintrusi }\end{array}$ \\
\hline SG 5 & 3516 & 3 & 345,72 & $\begin{array}{l}\text { Sedang } \\
\text { Terintrusi }\end{array}$ \\
\hline SG 6 & 3586 & 4 & 247,23 & $\begin{array}{l}\text { Sedang } \\
\text { Terintrusi }\end{array}$ \\
\hline SG 7 & 3656 & 2 & 248,16 & $\begin{array}{l}\text { Sedang } \\
\text { Terintrusi }\end{array}$ \\
\hline SG 8 & 3726 & 3 & 333,33 & $\begin{array}{l}\text { Sedang } \\
\text { Terintrusi }\end{array}$ \\
\hline SG 9 & 3826 & 4 & 357,41 & $\begin{array}{c}\text { Sedang } \\
\text { Terintrusi } \\
\text { Agak }\end{array}$ \\
\hline SG 10 & 3926 & 4 & 469,56 & $\begin{array}{l}\text { Tinggi } \\
\text { Terintrusi }\end{array}$ \\
\hline SG 11 & 4026 & 4 & 378,25 & $\begin{array}{l}\text { Sedang } \\
\text { Terintrusi }\end{array}$ \\
\hline SG 12 & 4126 & 6 & 360,19 & $\begin{array}{l}\text { Sedang } \\
\text { Terintrusi }\end{array}$ \\
\hline SG 13 & 4326 & 3 & 566,67 & $\begin{array}{l}\text { Tinggi } \\
\text { Terintrusi }\end{array}$ \\
\hline SG 14 & 4396 & 3 & 637,45 & $\begin{array}{l}\text { Tinggi } \\
\text { Terintrusi }\end{array}$ \\
\hline SG 15 & 4466 & 4 & 1038,32 & $\begin{array}{l}\text { Tinggi } \\
\text { Terintrusi }\end{array}$ \\
\hline SG 16 & 4536 & 3 & 907,51 & $\begin{array}{c}\text { Tinggi } \\
\text { Terintrusi } \\
\text { Agak }\end{array}$ \\
\hline SG 17 & 4786 & 4 & 528,97 & $\begin{array}{l}\text { Tinggi } \\
\text { Terintrusi } \\
\text { Agak }\end{array}$ \\
\hline SG 18 & 5036 & 5 & 448,15 & $\begin{array}{l}\text { Tinggi } \\
\text { Terintrusi }\end{array}$ \\
\hline SG 19 & 5286 & 7 & 246,28 & $\begin{array}{l}\text { Sedang } \\
\text { Terintrusi }\end{array}$ \\
\hline SG 20 & 5536 & 8 & 750 & Tinggi \\
\hline
\end{tabular}

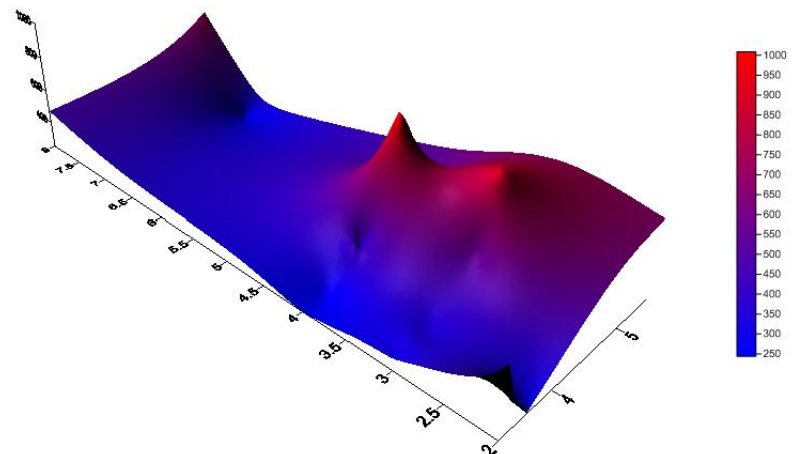

Gambar 2. Kontur Daya Hantar Listrik (DHL) Air Sumur Gali ( $\left.\mu \mathrm{mho} / \mathrm{cm}, 25^{\circ} \mathrm{C}\right)$ Terhadap Jarak (m) dan Kedalaman (m)

\section{Analisis Air Sumur Gali}

Data DHL air laut diambil dari sampel AL4 dengan DHL tertinggi.

Tabel 5. Data Analisis Daya Hantar Listrik (DHL) Air Laut (sampel AL 4) Pada Perlakuan Laboraturium

\begin{tabular}{ccccc}
\hline $\begin{array}{c}\text { Aqubides } \\
(\mathrm{ml})\end{array}$ & $\begin{array}{c}\text { Salinitas } \\
(\mathrm{ppm})\end{array}$ & $\begin{array}{c}\text { DHL } \\
(\mu \mathrm{mho} / \mathrm{cm})\end{array}$ & $\begin{array}{c}\text { Suhu } \\
\left({ }^{\circ} \mathrm{C}\right)\end{array}$ & $\begin{array}{c}\text { DHL } \\
(\mu \mathrm{mho} / \mathrm{cm}, 25 \circ \mathrm{C})\end{array}$ \\
\hline 20 & 970 & 19500 & 25,5 & 19316,49 \\
60 & 769 & 15780 & 25,9 & 15514,69 \\
130 & 523 & 10410 & 25,6 & 10292,66 \\
230 & 378 & 7580 & 26,4 & 7383,59 \\
380 & 263 & 5330 & 26,6 & 51272,75 \\
580 & 194 & 3910 & 26,8 & 3768,70 \\
820 & 119 & 1747 & 24,8 & 1753,66 \\
1120 & 741 & 1484 & 24,1 & 1509,82 \\
1370 & 705 & 1416 & 23,7 & 1451,86 \\
1570 & 638 & 1260 & 23,1 & 1307,19 \\
1670 & 558 & 1119 & 22,7 & 1170,13 \\
1720 & 585 & 1169 & 22,6 & 1224,85 \\
1820 & 556 & 1115 & 21,7 & 1189,59 \\
1920 & 533 & 1070 & 21,8 & 1139,27 \\
2000 & 532 & 1049 & 22,3 & 1105,72 \\
2150 & 518 & 1033 & 22,2 & 1091,04 \\
2250 & 461 & 923 & 22,5 & 969,03 \\
2350 & 435 & 868 & 22,8 & 905,87 \\
2430 & 488 & 975 & 22,7 & 1019,55 \\
2480 & 482 & 957 & 23,0 & 994,80 \\
2500 & 445 & 882 & 23,0 & 916,84 \\
\hline & & & &
\end{tabular}


Rappel Situmorang dan Mentari, Analisis Pengukuran Daya Hantar Listrik Dan KomponenKomponen Air Sumur Gali Dengan Konduktivitimeter Di Desa Sialang Buah Kecamatan Teluk Mengkudu Kabupaten Serdang Bedagai

\section{Analisis Pengukuran Tingkat Keasaman (pH) Air Sumur Gali}

Analisi tingkat keasaman untuk mengetahui kelayakan ph

Tabel 6. Data Analisa Pengukuran Tingkat Keasaman (pH) Air Sumur Gali

\begin{tabular}{|c|c|c|c|c|c|}
\hline $\begin{array}{c}\text { Kode } \\
\text { Sampel }\end{array}$ & $\begin{array}{c}\text { Jarak } \\
(\mathrm{m})\end{array}$ & $\begin{array}{c}\text { Kedalaman } \\
\text { (m) }\end{array}$ & $\begin{array}{c}\mathrm{DHL} \\
(\mu \mathrm{mho} / \mathrm{cm})\end{array}$ & $\begin{array}{l}\text { Suhu } \\
\left({ }^{\circ} \mathrm{C}\right)\end{array}$ & $\mathrm{Ph}$ \\
\hline SG 1 & 3296 & 2 & 672 & 26,9 & 7,7 \\
\hline $\mathrm{SG} 2$ & 3346 & 3 & 327 & 26,9 & 7,6 \\
\hline SG 3 & 3396 & 2 & 512 & 27,0 & 7,1 \\
\hline SG 4 & 3446 & 2 & 411 & 27,0 & 7,1 \\
\hline SG 5 & 3516 & 3 & 372 & 26,9 & 7,0 \\
\hline SG 6 & 3586 & 4 & 267 & 27,0 & 7,1 \\
\hline SG 7 & 3656 & 2 & 270 & 27,2 & 6,1 \\
\hline SG 8 & 3726 & 3 & 360 & 27,0 & 6,8 \\
\hline SG 9 & 3826 & 4 & 386 & 27,0 & 6,9 \\
\hline SG 10 & 3926 & 4 & 509 & 27,1 & 6,9 \\
\hline SG 11 & 4026 & 4 & 407 & 26,9 & 6,9 \\
\hline SG 12 & 4126 & 6 & 389 & 27,0 & 7,3 \\
\hline SG 13 & 4326 & 3 & 612 & 27,0 & 7,3 \\
\hline SG 14 & 4396 & 3 & 691 & 27,1 & 7,4 \\
\hline SG 15 & 4466 & 4 & 1138 & 27,4 & 7,3 \\
\hline SG 16 & 4536 & 3 & 991 & 27,3 & 7,5 \\
\hline SG 17 & 4786 & 4 & 573 & 27,1 & 8,1 \\
\hline SG 18 & 5036 & 5 & 484 & 27,0 & 7,5 \\
\hline SG 19 & 5286 & 7 & 265 & 26,9 & 7,4 \\
\hline SG 20 & 5536 & 8 & 807 & 26,9 & 6,8 \\
\hline
\end{tabular}

Analisis Regresi Linear Berganda Pada Sumur Gali

Untuk menganalisa pengaruh jarak sumur gali dari garis pantai dan kedalaman sumur gali secara bersamasama terhadap daya hantar listrik (DHL) dilakukan analisis regresi linear berganda(Situmorang, R. 2003).

Harga-harga yang diperlukan untuk menentukan persamaan regresi linear berganda, uji statistic $\mathrm{F}$ dan perhitungan koefisien-koefisien korelasi.

Berdasarkan perhitungan diperoleh :

$$
\begin{aligned}
& \sum \mathrm{X}_{1}=76 \\
& \sum \mathrm{X}_{2}=82240 \quad \begin{array}{l}
\sum \mathrm{X}_{1}^{2}=340 \\
\sum \mathrm{X}_{2} \mathrm{Y}=40717395
\end{array} \\
& \sum \mathrm{X}_{2}{ }^{2}=346638160 \\
& \sum \mathrm{Y}=9646,21 \quad \sum \mathrm{X}_{1} \mathrm{X}_{2}=328816 \\
& \sum \mathrm{Y}^{2}=5559245 \\
& \mathrm{X}_{1}=3,8 \quad \mathrm{X}_{2}=4112 \\
& \mathrm{Y}=482,311 \\
& \mathrm{a}_{0}=-3799,46 \quad \mathrm{a}_{1}=17,81 \\
& \mathrm{a}_{2}=0,455
\end{aligned}
$$

Berdasarkan hasil perhitungan diperoleh persamaan regresi linear berganda yaitu :

$$
\mathrm{Y}=-17,81+17,81 X_{I}+0,455 X_{2}
$$

\section{Pembahasan}

Dari data pada tabel 6 diketahui bahwa dari 20 sumur gali yang dijadikan sampel telah terintrusi air laut dengan jumlah sumur gali yang terintrusi agak tinggi adalah 4 buah atau $20 \%$ dari 20 sumur gali yang dijadikan sampel. Jumlah sumur gali yang terintrusi sedang adalah 10 buah atau 50\% dari 20 sumur gali yang dijadikan sampel. Jumlah sumur gali yang terintrusi tinggi adalah 6 buah atau 30\% dari 20 sumur gali yang dijadikan sampel. Faktor kedalaman mempengaruhi DHL sebesar $1 \%$, sedangkan faktor jarak mempengaruhi DHL air sumur gali sebesar $14,2 \%$. Sehingga dapat dikatakan bahwa terdapat $85,7 \%$ faktor lain diluar faktor kedalaman dan jarak yang mempengaruhi DHL air sumur gali.

Menurut penelitian (Juanta, 2014) menyatakan bahwa jarak dan kedalaman sumur mempengaruhi daya hantar listrik (DHL) sebesar 0,04\%, sementara sisanya yakni $99,96 \%$ adalah pengaruh faktor diluar faktor jarak dan faktor kedalaman sumur. Dan dalam penelitian (Widada, 2011) menyatakan bahwa sumur gali dengan tingkat intrusi tertinggi pada sumur ke-10 yang berjarak 5962 meter dari garis pantai sedangkan tingkat intrusi terendah pada sumur ke-5 yang berjarak 5661 
meter dari garis pantai, hal ini menunjukkan bahwa jarak tidak menjadi faktor utama terhadap tingkat daya hantar listrik.

Dari penelitian (Soehartono, 2013) menyatakan bahwa pengaruh kedalaman terhadap DHL air sumur gali hanya 4\%. Hal ini menunjukan bahwa intrusi air laut jauh lebih besar dipengaruhi oleh faktor lain diluar faktor jarak. Penelitian lainnya yang menunjukan bahwa tingkat intrusi air dipengaruhi oleh faktor lain dilaur faktor jarak dan kedalaman adalah dalam penelitian (Grace, 2014) yang menyatakan bahwa tingkat intrusi terendah pada sumur ke 17 dan tingkat intrusi tertinggi pada sumur ke-6.

\section{KESIMPULAN}

Dari hasil penelitian yang diperoleh dapat disimpulkan :

1. Semua sumur gali di Desa Sialang Buah Kecamatan Teluk Mengkudu Kabupaten Serdang Bedagai telah terintrusi mulai dari tingkat rendah hingga terintrusi tingkat tinggi berdasarkan Daya Hantar Listrik (DHL) dengan sumur gali ke-19 yang berjarak 5286 meter dan kedalaman 7 meter (terintrusi rendah) dan sumur gali dengan Daya Hantar Listrik (DHL) tertinggi pada sumur gali ke-15 yang berjarak 4466 metrer dan kedalaman 4 meter.

2. Air sumur gali memiliki keasaman berkisar 6,1 - 7,5. Dan sumur gali ke-17 memiliki pH diatas standar kelayakan air untuk dikonsumsi yaitu 8,1. Namun melihat kualitas air sumur gali dari 20 sampel yang diteliti bahwa air sumur gali tersebut telah terintrrusi maka dapat dinyatakan tidak layak/tidak dapat dikonsumsi.

3. Air sumur gali memiliki kualitas air dengan kategori terintrusi sedang, terintrusi agak tinggi dan terintrusi tinggi.

Saran

Melihat air sumur gali di Desa Sialng Buah Kecamatan Teluk Mengkudu Kabupaten Serdang Bedagai memiliki tingkat Daya Hantar Listrik yang telah melewati batas standar kualitas air layak konsumsi maka agar penduduk setempat tidak menggunakan air sumur gali tersebut untuk dikonsumsi.Dan agar Pemerintah setempat segera memperhatikan air minum yang akan dikonsumsi tersebut.

\section{DAFTAR PUSTAKA}

Grace. 2014. Analisis Intrusi Air Laut dan Kandungan Logam Berat pada Air Sumur Gali Dan Sumur Bor Di Kecamatan Hamparan Perak.Skripsi.Unimed : Medan.

Juanta. 2014. Analisis Intrusi Air Laut dan Kandungan Logam Berat pada Air Sumur Gali Dan Sumur Bor Di Belawan.Skripsi.Unimed : Medan.

Nurrohim, A.2012. Kajian Intrusi Air Laut Di Kawasan Pesisir Kecamatan Rembang Kabupaten Rembang. ISSN 2252-6285

Situmorang, R. 2003. Pendeteksian Intrusi Air Laut Di Sekitar Kawasan

Industri Kimia Medan (KIM) Dengan Metode Konduktivitas Listrik,Tesis,program Pasca Sarjana USU : Medan.

Soehartono.2013. Pendugaan Intrusi Air Laut Dengan Menggunakan Metode Geolistri Resistivitas 1D Di Pantai Payangan Desa Sumberrejo Jember.Vol. 1 No. 1 Hal 10.

Widada. 2011. Pengaruh Kenaikan Permukaan Air Laut pada Intrusi Air Laut di Akuifer Pantai.Vol. 2 No. 3.Hal 12.ITS : Surabaya 